\title{
An Approach for Real World Data Modelling with the 3D Terrestrial Laser Scanner for Built Environment
}

\author{
Yusuf Arayici \\ School of Construction and Property Management \\ University of Salford \\ United Kingdom \\ y.arayici@salford.ac.uk
}

Capturing and modelling 3D information of the built environment is a big challenge. A number of techniques and technologies are now in use. These include EDM, GPS, and photogrammetric application, remote sensing and traditional building surveying applications. However, use of these technologies cannot be practical and efficient in regard to time, cost and accuracy. Furthermore, a multi disciplinary knowledge base, created from the studies and research about the regeneration aspects is fundamental: historical, architectural, archeologically, environmental, social, economic, etc. In order to have an adequate diagnosis of regeneration, it is necessary to describe buildings and surroundings by means of documentation and plans. However, at this point in time the foregoing is considerably far removed from the real situation, since more often than not it is extremely difficult to obtain full documentation and cartography, of an acceptable quality, since the material, constructive pathologies and systems are often insufficient or deficient (flat that simply reflects levels, isolated photographs,..). Sometimes the information in reality exists, but this fact is not known, or it is not easily accessible, leading to the unnecessary duplication of efforts and resources.

In this paper, we discussed 3D laser scanning technology, which can acquire high density point data in an accurate, fast way. Besides, the scanner can digitize all the 3D information concerned with a real world object such as buildings, trees and terrain down to millimetre detail Therefore, it can provide benefits for refurbishment process in regeneration in the Built Environment and it can be the potential solution to overcome the challenges above. The paper introduce an approach for scanning buildings, processing the point cloud raw data, and a modelling approach for CAD extraction and building objects classification by a pattern matching approach in IFC (Industry Foundation Classes) format. The approach presented in this paper from an undertaken research can lead to parametric design and Building Information Modelling (BIM) for existing structures. Two case studies are introduced to demonstrate the use of laser scanner technology in the Built Environment. These case studies are the Jactin House Building in East Manchester and the Peel building in the campus of University Salford. Through these case studies, while use of laser scanners are explained, the integration of it with various technologies and systems are also explored for professionals in Built Environment.

Key words: 3D laser scanner, CAD, pattern matching, integration, visualisation

\section{INTRODUCTION}

Advanced digital mapping tools and technologies so-called 3D laser scanner are enablers for effective e-planning, consultation and communication of users' views during the planning, design, construction and lifecycle process of built and human 
environments. The regeneration and transformation of cities from the industrial age (unsustainable) to the knowledge age (sustainable) is essentially a 'whole life cycle' process consisting of; planning, development, operation, reuse and renewal (Arayici and Hamilton, 2005a). In order to enhance the implementation of build and human environment solutions during the regeneration and transformation of cities, advanced digital applications can have a significant impact (Arayici and Hamilton, 2005b).

This innovation is significant because it has potential to solve the problems that are always been associated with design and construction of existing buildings. It can provide faster, better quality and more precise analysis and feature detection for building survey (Arayici et al, 2004). Within the built environment, the use of the 3D laser scanner enables digital documentation of buildings, sites and physical objects for reconstruction and restoration including cultural heritage. It also enables the creation of educational resources within the built environment, as well as the reconstruction of the built environment. Besides, it has also potential to accurately record inaccessible and potentially hazardous areas. As a result, it can facilitate "virtual refurbishment" of the buildings and allows the existing structure and proposed new services to be seen in an effective manner. The use of the 3D scanner in combination with building and city systems is key enablers to the creation of new approaches to the 'Whole Life Cycle' process within the built and human environment for the 21st century.

Besides, the 3D Laser Scanners in the natural environment also allow constructing Digital Elevation Models (DEMs) that accurately represent landform surface variability and offer an excellent opportunity to measure and monitor morphological change across a variety of spatial scales such as flooding scenarios and the causes of potential flooding in the natural environment (Brasington et al. 2000; Fuller et al. 2005) (Hetherington et al, 2005). Although many studies have been conducted in the natural environment to collect spatial data by means of sophisticated surveying equipment such as aerial LIDAR, EDM theodolites, GPS, photogrammetry, many of these studies continue to suffer area or resolution limitations due to a trade off between spatial coverage and morphologic detail captured (Hetherington et al, 2005). For example, techniques such as terrestrial photogrammetry produce dense accurate morphometric data but aerial coverage is restricted, aerial photogrammetry offers increased spatial coverage but reduced elevation accuracy, EDM surveys suffer from long collecting times resulting in reduced data density if large areas are surveyed (Hetherington et al, 2005). Besides, traditional building surveying techniques also suffer for accurate and complete data capture due to accessibility and manual measurement and laborious activities on field. For example, due to various hazards building surveyors may have accessibility problems on site, which leads them to estimation. As a result, that causes inconsistency in accurate data capture.

In this paper use of laser scanner and its potential benefits for the built environment is explained based on the research studies undertaken in the built and natural environment fields. In the following section, background information and literature search are presented in the research studies in regard to 3D laser scanner. This includes technical description of 3D laser scanner concept, use of this technology in the literature, the vision for the use of this technology and the limitations experienced in the initial experiments of this tool in the research studies in the built and natural environment. 


\section{BACKGROUND}

The 3D laser scanner is targeted to the physical objects to be scanned and the laser beam is directed over the object in a closely spaced grid of points. By measuring the time of laser flight, which is the time of travel of the laser from the scanner to the physical objects and back to the scanner, the position in three-dimensional space of each scanned point on the object is established. The result is a "cloud of points" which consists in thousands of points in 3-dimensional space that are a dimensionally accurate representation of the existing object This information can then be converted into a 3D CAD model that can be manipulated using CAD software, and to which the design of the new equipment can be added (Schofield, 2001), (Bornaz \& Rinaudo, 2004).

Terrestrial laser scanners are being used more frequently in built and natural environment due to their high data acquisition rate, high accuracy and high spatial data density. Though parameters vary from instrument to instrument, acquisition rates vary from 1 to $6 \mathrm{kHz}$, ranging accuracy varies from $5 \mathrm{~mm}$ to $25 \mathrm{~mm}$ and sampling interval is generally programmable, which result in the laser scanning technology attain advantages over current survey techniques including EDM, GPS and photogrammetric applications, obtaining high density point data without the need for a reflector system (Heritage and Hetherington, 2005). Merged data clouds have sufficient points to negate the need for EDM interpolation techniques potentially providing the optimum representation of any scanned surface (Lichti, 2004). 3D laser mapping enables the recording of slight differences that exist in the physical world and has been used for a variety of sectors which range from industrial applications for process automation in automotive industry to robotics and from archaeology to virtual reality (Arayici and Hamilton, 2005a), (Li et al 2004).

For example, the great Budda of Kamakura, which is a valuable heritage treasure of Japan who created a digital model of the Buddha to preserve it for all time (Ikeuchi and Sato, 2001), (Miyazaki et al, 2000), (Andreoni \& Pinto, 2004), (Bouroumand \& Studnicka, 2004). Another example is virtual tourism: A 3D model of the landmark would allow for user interaction, enabling visitors to explore an ancient site (Huber 2002), (Georgopoulos et al, 2004), (Yamada \&Takase, 2004). It can enable visitors to explore the historical places and monuments without travelling around the world by means of virtual tourism as long as the experience is to be realistic to people.

Depending on the application, different aspects of a digital model may be important. With some applications, such as quality control of manufacture parts, geometric accuracy is crucial. In other cases, such as virtual tourism, precise geometry is not as critical as photometric accuracy (Huber 2002). The research studies has proven that the 3D laser scanners are effective sensing modality for creating accurate models (Huber (2002), (Bernardini and Rushmeier, 2000), (Allen et al, 2001).

Owing to exposure to the elements, many historical sites are slowly deteriorating. Although remediation efforts can reduce the rate of destruction, a digital model of the site will preserve it indefinitely. Examples of this type project work include the Digital Michelangelo project (Levoy, 1999), (Levoy et al, 2000), Castel Del Monte project (Capra et al, 2005), The Baranole Palace at Avio's Castle (Campanella et al, 2005), Ss. Pietro e Paolo Church in Morano Calabro (Artese et al, 2005) and many 
more. Models of historical artefacts also allow scientists to study the objects in new ways. For example, archaeologists can measure artefacts in a non-contact fashion, which is useful for fragile objects. Also digital models allow objects to be studied remotely, saving time and travel expenses and enabling more archaeologists to study them (Huber 2002), (Fidera et al, 2004), (Bryan et al, 2004). Besides, in civil and structural engineering, 3D laser scanning provides an efficient to surveying. For example, bridges need to be surveyed periodically to determine whether significant settling or other movement has occurred. A 3D model of the site allows engineers to make the same measurements with equivalent accuracy in a period of time.

On the other hand, in the film industry special effects companies often use 3D models of movie sets to realistically integrate computer generated effects with live action. In regard to reverse engineering and rapid prototyping, 3D laser scanner can be sued to reverse engineer manufactured parts for which a CAD model is unavailable or never existed. For example, a design engineer at an auto manufacturer might create a handcarved model of a prototype car. Modelling from reality imports the prototype into a computer, creating a digital model that can be edited with a CAD program (Huber, 2002), (Sternberg et al, 2004).

Robots navigating over rough terrain benefit from 3D models for route planning and obstacle avoidance. In the Mars Pathfinder mission, 3D models of the area around the base station allowed scientists to visualise the environment and direct the rover's daily travels. Automated 3D modelling methods would have significantly reduced the man hours required for this task (Huber 2002).

In regard to virtual reality, instead of developing virtual environments by hand, as in common practice today, real environments can be modelled. For example, 3D models of houses would allow virtual walkthroughs for the real-estate market. Museums and historical sites could create virtual tours, which would be educational as well as entertaining (Huber, 2002).

As summarised above, 3D laser scanner has an immense potential, it is hardly used for building refurbishment and in regeneration projects which requires intensive knowledge capturing from the existing world and communication and information exchange platforms and tools. However, 3D laser scanner technology can provide fast and accurate geospatial data capture, which then can be modelled into the appropriate formats for effective decision making, production of plans and elevations in digital environment, Virtual Reality (VR) models development for public participation and support the community based regeneration projects.

Research Institute of Built and Human Environment at the University of Salford make use of a Riegl LMS-Z210 3D laser scanner for construction research with PolyWorks software for processing the point data into a 3D model. The LMS-Z210 3D imaging sensor is a rugged and fully portable sensor for the rapid acquisition of high-quality three-dimensional images even under highly demanding environmental conditions. The scanner provides a combination of wide field-of-view, high accuracy, and fast data acquisition. The scanner is connected to a $12 \mathrm{~V}$ battery and a ruggedised laptop.

The high-speed scanner has the following specifications:

o Maximum measurement range $=300 \mathrm{~m}$ (in typical conditions) 
o Minimum measurement range $=2 \mathrm{~m}$

o Measurement accuracy $=$ typical $+/-25 \mathrm{~mm}$

o Measurement resolution $=25 \mathrm{~mm}$

o Beam divergence $=$ approx. $3 \mathrm{mrad}$ (i.e. $30 \mathrm{~cm}$ beam width per $100 \mathrm{~m}$ range)

o Field of view $=80^{\circ}$ vertical angle, $333^{\circ}$ horizontal angle

o Scanning rate $=6000$ points per second

o Class I eye-safe laser

This scanner was one of the best scanners when the scanner purchased in 2003. However, today there are better scanners with higher specifications. Since the author has familiar with Riegl scanners a comparative table for Riegl scanners are shown below. Although there are other brands of 3D laser scanners, it is envisaged that Riegl scanners are the most appropriate ones for built and urban environment due to field of view, long scanning range and scanning accuracy despite the long range and field of view, robust data handling and processing by companion and well-linked third party software tools.

\begin{tabular}{|c|c|c|c|c|c|}
\hline & \multicolumn{3}{|c|}{ 3D-Imaging Scanner Systems } & \multicolumn{2}{|c|}{$\begin{array}{l}\text { 3D-Laser Profile Measuring } \\
\text { Systems } \\
\end{array}$} \\
\hline Type & $\underline{\text { LMS-Z420i }}$ & $\underline{\text { LMS-Z390 }}$ & LMS-Z210ii & LPM-i800HA & LPM-2K \\
\hline Main Specs & $\begin{array}{c}\text { High- } \\
\text { Accuracy, } \\
\text { Long Range } \\
\text { \& High-- } \\
\text { Speed } \\
\end{array}$ & $\begin{array}{c}\text { High- } \\
\text { Accuracy \& } \\
\text { High } \\
\text { Resolution }\end{array}$ & $\begin{array}{l}\text { General } \\
\text { Purpose }\end{array}$ & $\begin{array}{c}\text { High-Accuracy } \\
\& \\
\text { Long-Range }\end{array}$ & Long-Range \\
\hline eye safety & $\begin{array}{c}\text { Laser Class } \\
1 \\
\end{array}$ & $\begin{array}{c}\text { Laser Class } \\
1 \\
\end{array}$ & $\begin{array}{c}\text { Laser Class } \\
1\end{array}$ & Laser Class 1M & Laser Class 1M \\
\hline min range & $2 \mathrm{~m}$ & $1 \mathrm{~m}$ & $4 \mathrm{~m}$ & $10 \mathrm{~m}$ & $10 \mathrm{~m}$ \\
\hline $\begin{array}{c}\text { max range } \\
\mathrm{r}^{3} 80 \% \\
\mathrm{r}^{3} 80 \% \\
\end{array}$ & $\begin{array}{c}1000 \mathrm{~m} \\
350 \mathrm{~m}\end{array}$ & $\begin{array}{l}300 \mathrm{~m} \\
100 \mathrm{~m}\end{array}$ & $\begin{array}{l}650 \mathrm{~m} \\
200 \mathrm{~m}\end{array}$ & $\begin{array}{l}800 \mathrm{~m} \\
250 \mathrm{~m}\end{array}$ & $\begin{array}{l}2500 \mathrm{~m} \\
800 \mathrm{~m}\end{array}$ \\
\hline $\begin{array}{c}\text { Repeatability } \\
\text { Averaged } \\
\text { Single shot }\end{array}$ & $\begin{array}{l}4 \mathrm{~mm} \\
8 \mathrm{~mm}\end{array}$ & $\begin{array}{l}2 \mathrm{~mm} \\
4 \mathrm{~mm}\end{array}$ & $\begin{array}{l}10 \mathrm{~mm} \\
15 \mathrm{~mm}\end{array}$ & $\stackrel{-}{15 \mathrm{~mm}}$ & $\begin{array}{c}- \\
50 \mathrm{~mm}\end{array}$ \\
\hline accuracy & $10 \mathrm{~mm}$ & $6 \mathrm{~mm}$ & $15 \mathrm{~mm}$ & - & - \\
\hline $\begin{array}{l}\text { Field of view } \\
\text { Line scan } \\
\text { Frame scan }\end{array}$ & $\begin{array}{l}\text { 80deg } \\
\text { 360deg }\end{array}$ & $\begin{array}{l}80 \mathrm{deg} \\
360 \mathrm{deg}\end{array}$ & $\begin{array}{l}80 \mathrm{deg} \\
360 \mathrm{deg}\end{array}$ & $\begin{array}{l}-20 /+130 \mathrm{deg} \\
360 \mathrm{deg}\end{array}$ & $\begin{array}{l}-60 /+130 \mathrm{deg} \\
360 \mathrm{deg}\end{array}$ \\
\hline angular resolution & $0.0025 \mathrm{deg}$ & 0.001 deg & $0.005 \mathrm{deg}$ & 0.009deg & $0.009 \mathrm{deg}$ \\
\hline $\begin{array}{l}\text { Measurement per } \\
\text { seconds } \\
\text { Rotating mirror } \\
\text { Oscillating mirror }\end{array}$ & $\begin{array}{l}\text { Up to } 8000 \\
\text { Up to } 12000\end{array}$ & $\begin{array}{l}\text { Up to } 8000 \\
\text { Up to } 12000\end{array}$ & $\begin{array}{l}\text { Up to } 8000 \\
\text { Up to } 12000\end{array}$ & typically 1000 & up to 4 \\
\hline laser wavelength & near IR & near IR & near IR & near IR & near IR \\
\hline beam divergence & $0.25 \mathrm{mrad}$ & $0.25 \mathrm{mrad}$ & $2.7 \mathrm{mrad}$ & $1.3 \mathrm{mrad}$ & $1.2 \mathrm{mrad}$ \\
\hline data interface & TCP/IP & TCP/IP & TCP/IP & TCP/IP \&RS 422 & TCP/IP\&RS 422 \\
\hline 3D Projects & $\underline{\text { LMS-Z420i }}$ & $\underline{\text { LMS-Z390 }}$ & $\underline{\text { LMS-Z210ii }}$ & LPM-i800HA & LPM-2K \\
\hline $\begin{array}{c}\text { Archaeology \& } \\
\text { Cultural Heritage } \\
\text { Documentation }\end{array}$ & $\bullet \bullet \bullet$ & $\bullet \bullet \bullet \bullet$ & - & $\bullet$ & - \\
\hline $\begin{array}{l}\text { Architecture\&Façade } \\
\text { Measurements }\end{array}$ & $\bullet \bullet \bullet$ & $\bullet \bullet \bullet$ & - & - & - \\
\hline City Modelling & $\bullet \bullet \bullet$ & $\bullet \bullet \bullet$ & - & - & - \\
\hline
\end{tabular}




\begin{tabular}{|c|c|c|c|c|c|}
\hline Civil Engineering & $\bullet \bullet \bullet$ & $\bullet \bullet \bullet$ & - & $\bullet \bullet$ & - \\
\hline Monitoring & $\bullet \bullet \bullet$ & - & $\bullet \bullet \bullet$ & $\bullet \bullet \bullet$ & $\bullet \bullet \bullet$ \\
\hline $\begin{array}{c}\text { Process Automation } \\
\text { \& Robotics }\end{array}$ & - & $\bullet$ & $\bullet \bullet \bullet$ & - & - \\
\hline As-Built Surveying & $\bullet \bullet \bullet$ & $\bullet \bullet \bullet$ & - & - & - \\
\hline Topography\&Mining & $\bullet \bullet \bullet$ & $\bullet \bullet$ & $\bullet \bullet \bullet$ & $\bullet \bullet \bullet$ & $\bullet \bullet \bullet$ \\
\hline Tunnel Surveying & - & $\bullet \bullet \bullet$ & - & - & - \\
\hline Virtual Reality & $\bullet \bullet \bullet$ & $\bullet \bullet \bullet$ & $\bullet$ & - & - \\
\hline$\bullet \bullet \bullet \quad$ Excellent for the selected applications, $\bullet \bullet \quad$ very good $\bullet$ good
\end{tabular}

Table 1: Comparison of Different Riegl Scanners in regard to their specification and their use in different applications www.riegl.com, (Note: LMS-Z210ii is the twice upgraded version of the scanner used in the case studies in this paper)

During data acquisition, the 3D-RiSCAN software is used. It allows the operator to perform a large number of tasks including sensor configuration, data acquisition, data visualization, data manipulation, and data archiving. Numerous export functions allow the scanned data to be passed to post-processing data packages.

A field methodology to rapidly capture data is used for surveying. For each scanner position, first a scan of the full field of view ( $333^{\circ}$ horizontally) is made to aid merging of data from subsequent scan positions and to aid the definition of detailed scans. Next, one or more detailed scans are made with a finer resolution of the area of interest (typically the building). Scan time varies from 10 seconds to 240 seconds dependent on the required resolution. This methodology is being extended to incorporate GPS positioning of the scanner.

Following the data capture, post processing is conducted in the office. Polyworks software (produced by Innovmetric Software Inc.) provides comprehensive set of tools for quickly processing 3D scanned data. The software can handle many millions of data points while still retaining the ability to model very fine details very accurately. It will allow scans from each scanner position to be merged together in space. The software will compare geometric features in overlapping areas of adjacent scans to calculate the correct alignment of each scan. This is a very accurate method of aligning laser scan data as it is using many thousands of measurements to make a comparison rather than a few observations that would be made in a conventional surveying scenario. Next, the 3D mesh model (termed a wireframe) is created. This 3D mesh uses all the measured data points without applying any dangerous point sampling techniques. In its approach, it uses tolerance-based smoothing and tolerancebased adaptive meshing which provide a robust industrial strength process (Arayici et al, 2004). The 3D model can then be viewed, analysed and edited as necessary. It is also possible to use an intelligent simplification algorithm on the model to reduce the number of triangle vertices while retaining as much information as possible especially on edges.

\subsection{Research Perspectives for the 3D Laser Scanner Technology in the Built Environment}

The scope includes the integration of the laser scanning system with the existing and other innovative systems. A SCRI (Salford Centre for Research and Innovation) workshop was held in October 2004 and stakeholders of a broad range of disciplines 
from industry and academia in the Built environment have attended to the workshop. A common idea emerged from the workshop was that research perspectives lays in the integration of 3D laser scanner with other building and city systems to provide digital information from the existing world. As a result, decision making activities can be carried out more effectively and accurately.

The figure 1 below illustrates the scope of the research by means of use cases, which shows the potential integration of the 3D laser scanner with other systems. That includes the CAD system for $2 \mathrm{D}$ and $3 \mathrm{D}$ CAD plans, with the $2 \mathrm{D}$ topographic data, with the VR projection system for visualisation, with the 3D printing system for physical modelling for presentation and with the $\mathrm{nD}$ modelling repository for storing the IFC information produced from the laser scanning system in a database for effective decision making during the refurbishment process.

Use cases were developed as outlines of the 3D laser scanning system before delving into the details. In this activity, the use cases were used for the conceptual modelling of what the system should do from the user's point of view. Thus, use cases act as the common language for communication between the stakeholders. The use case diagram below (figure 1) further elaborates the interaction and integration of the laser scanning systems with the other systems within the INTELCITIES scope (www.intelcitiesproject.com). 9 use cases are defined. These use cases describes the vision for the use of the system for the refurbishment process in regeneration.

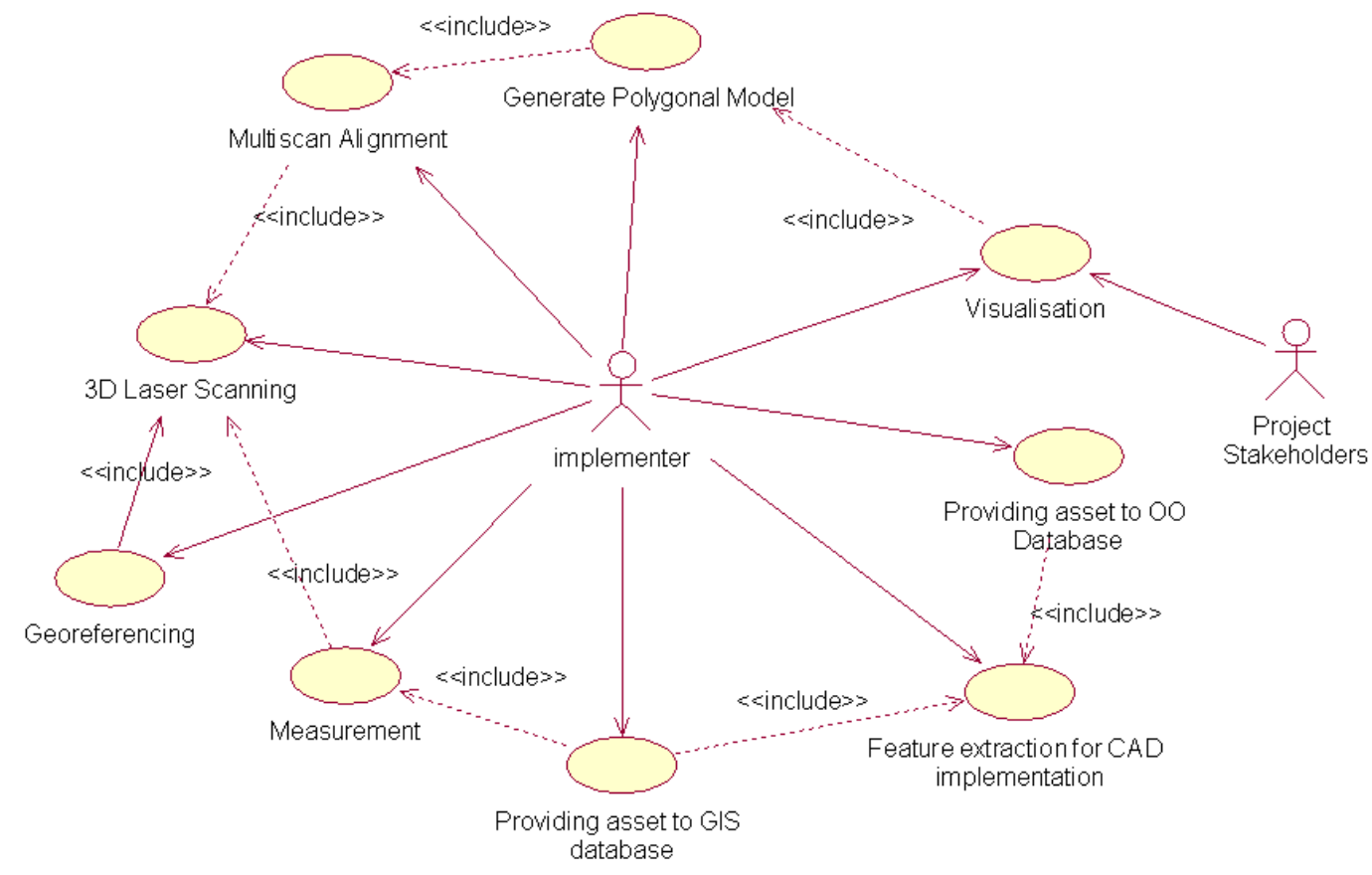

Figure 1: Research scope for potential use of laser scanner in integration with other systems in the built environment that includes modelling Object-Oriented IFC information from the 3D laser scanner data.

These use cases are as follows:

1. 3D Laser Scanning

2. Multiple Scan Alignment 

3. Generate Polygonal Model
4. Georeferencing
5. Measurement
6. Feature Extraction for CAD implementation
7. Providing asset to OO Database (nD modelling)
8. Providing asset to GIS database
9. Visualisation

In the next section, the limitations ands lessons learnt from initial experiments of the above use cases are explained.

\subsection{Early Limitations and Lessons Learnt}

Through the attempt for integration with the above systems, the main limitation is the extracting the meaningful information from the 3D model produced from 3D laser scanning system. This is because the laser scanner acquires millions of point data of the existing objects which also includes $\mathrm{X}, \mathrm{Y}, \mathrm{Z}$ and RGB information for individual points in the point cloud data. As result, it brings about the difficulty in extracting geometric information accurately and fast from non-meaningful data such as feature lines for 2D and 3D CAD plans and models.

Otherwise, use of the post-processed model of the laser scanning system is not easy to handle for the other systems. Therefore, particular attention must be paid during the analysis, the processing and the modelling phases of the laser scanner data (Bornaz, \& Rinaudo, 2004). In the following subsections the specific limitations are described.

\subsubsection{Limitations in integration with the CAD systems}

The laser scanner system enables to produce a polygonal mesh model of the existing buildings and provides export facilities in various CAD oriented data formats. However, this model is not directly useful for developing the 2D and 3D CAD models, which is aimed at using for building refurbishment process. This is because the polygonal model is formed by a large number of triangles, which needs extracting the features lines for CAD modelling.

However, it is not sufficiently accurate to extract the feature lines using the crosssections and curves, which do not provide straight lines as an output. There is not yet fast, fully automated and accurate process is identified for the extraction of feature lines. Cross sectioning can be considered for extraction of 2D bird-eye view CAD plans using a mode of indoor scans. However, it is not sufficient for an ideal bird-eye view CAD plan because wall thickness cannot be obtained accurately unless reflectors are used during the scanning process.

In order for fully automated and accurate extraction of feature lines for CAD modelling, a specific approach is identified, which includes use of planes and crosssections. In the approach, the planes are inserted through each surface in the model. All the vertices deviated from the plane are projected to the plane, which result in a very smooth surface before cross-sectioning. This activity is applied to every surface, when this activity completed, cross-sections are applied through the same planes to each surface. All cross-sections are exported in dxf or IGES formats for analysis in CAD software such as Microstation. The output in Microsation will be a 2D or 3D CAD models with straight lines. 
However, this approach requires long time for editing in the Polyworks software and currently it is investigated to reduce the editing period by improving the quality of the models during the process and further functional developments.

\subsubsection{Limitations in Integration with the 3D Printing System}

The 3D printing system only accepts files in STL format and it uses wax and plastic to make the shape of the model. Therefore, the model should be closed shape or the surfaces should have thickness for a complete and accurate printing.

On the other hand, the polygonal model produced in the laser scanning system has very thin surfaces. It is easy to produce the STL format of the same model. However, it is not appropriate for 3D printing because of the thin surfaces in the model. In order to overcome this limitation, after completing the editing process in Polywork software, the model is exported in dxf format to the Microstation CAD software to extrude the model in the third dimension to create thickness in the model. However, exporting the extruded model from Microstation sometimes is not sufficient because the STL export of the extruded model has irrelevant holes in the model, which makes the model incomplete for 3D printing. This is attributable to the arbitrary triangles make up the model.

In the next section, research methodology for the paper is introduced. It explains how laser scanner technology has been experimented in association with other systems to demonstrate the integration depicted in figure 1 and the use cases in figure 2 .

\section{RESEARCH METHODOLOGY}

This section describes the various stages adopted for the 3D laser scanner data capturing, processing, modelling and integration. The research strategy is a case study research strategy. The case studies are the Peel building in the campus of university of Salford, the Jactin house building in East Manchester. The goal of the research methodology is to describe a systematic mechanism to achieve the use cases to demonstrate a process for the integration of 3D laser scanner with the other systems depicted in figure 1 . The process in the methodology was described in a sequential manner to illustrate the use of outputs from each phase as an input for the following phases in an accumulative manner. Through the methodology, the paper explains the point cloud data capture, processing and modelling. The process flow of the CAD extraction approach is prescribed in figure 2 . 


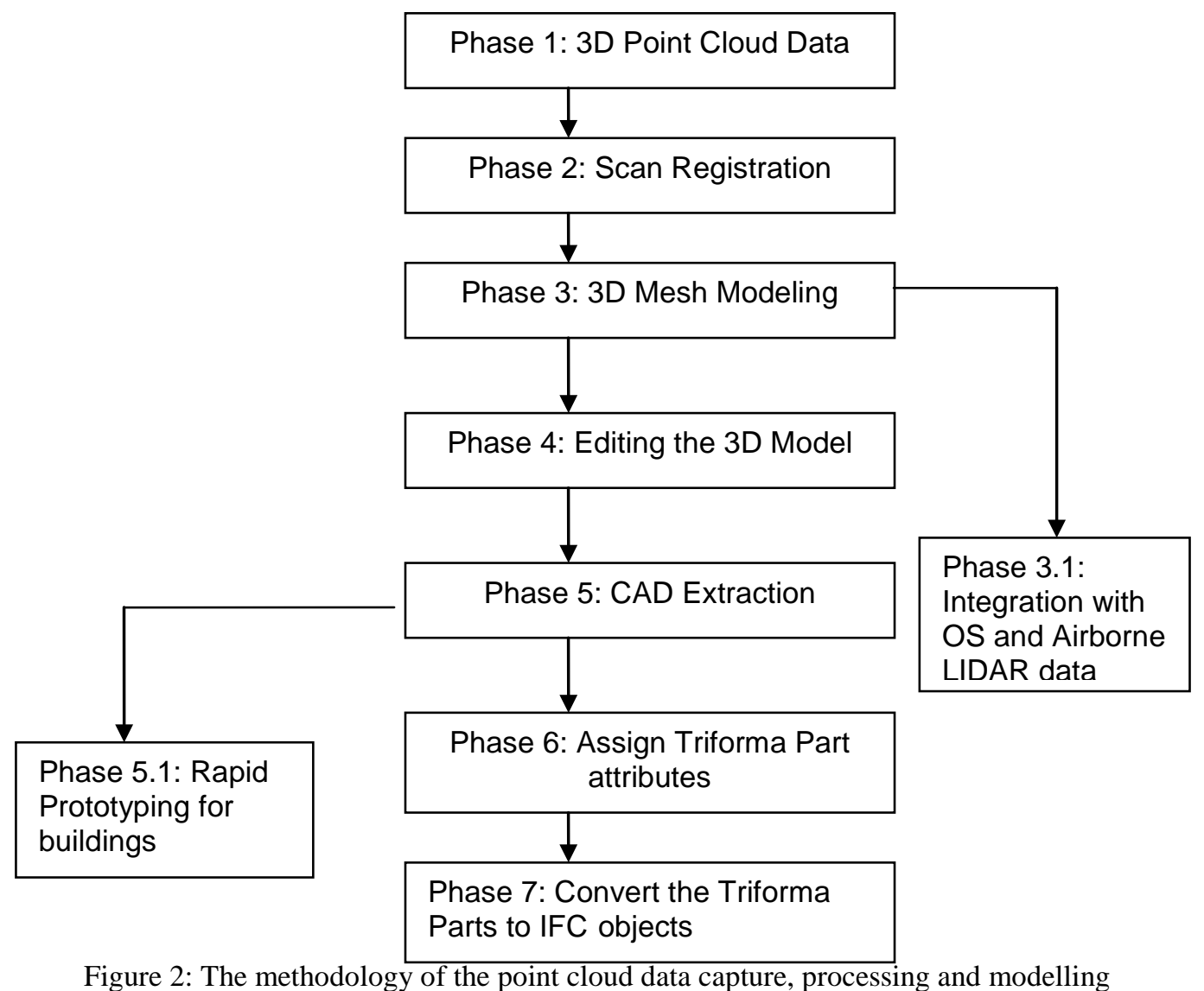

In the methodology while the scanner data is processed and modelled through the phases in figure 2, the integration with the other systems is also achieved.

\subsection{Point Cloud Data Capture, Processing and Modelling}

3D point cloud data can be captured using the laser scanner together with the RiSCAN Pro software during phase 1. Scan registration at phase 2 can be comfortably done in either RiSCAN Pro software or the Polyworks IMAlign software module based on project requirements and scanning strategy. While the point cloud capture, processing and modelling for feature lines extraction is shown in figure 3 below with a diagram, figures from 4 to 8 shows images from the process. For example, figure 4 and 5 shows individual 3D scans from the Peel building and Jactin house case studies. Figure 6 illustrates the scan registration and adjustment and figure 7 and 8 depicts final mesh models produced individual scans around the case study buildings. 


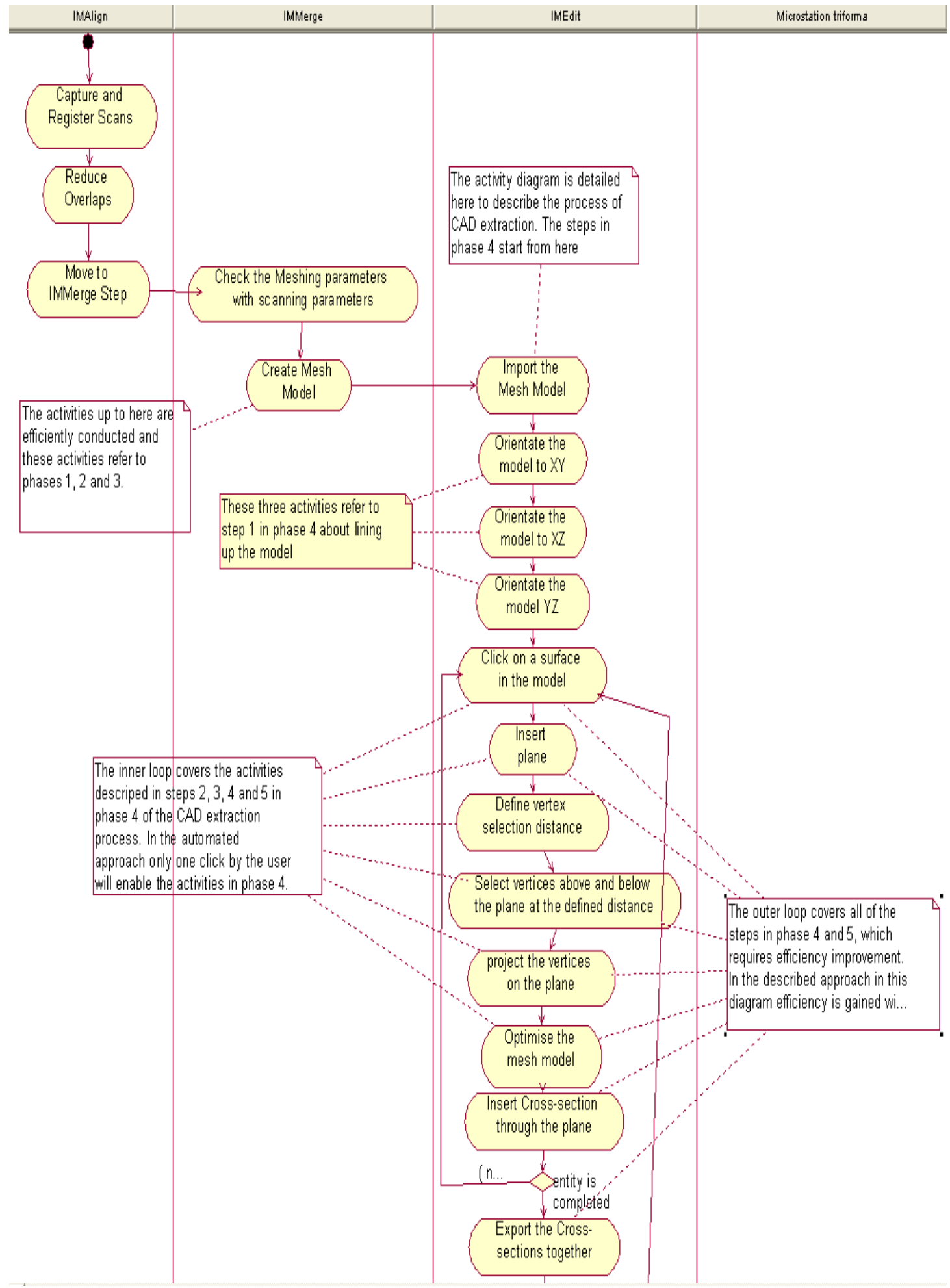

Figure 3: Process for Feature line extraction for CAD Modelling

Once all the scans are registered, a point cloud model of the scanned object is obtained. A 3D mesh model can be generated using the IMMerge Module of Polyworks software. Meshing parameters such as surface sampling step, reduction tolerance, smoothing and maximum distance, are important to create smooth and filtered high quality mesh model with high resolution. To achieve this, it is important to take into account the scanning parameters. The accuracy and resolution of the 
model will be dependent on the scanning resolution and the laser scanner accuracy. The output from ImMerge is a polygonal mesh model of the building, scene or object that has been scanned and merged. The final merged model can then be exported from IMMerge and imported into IMEdit for refining.

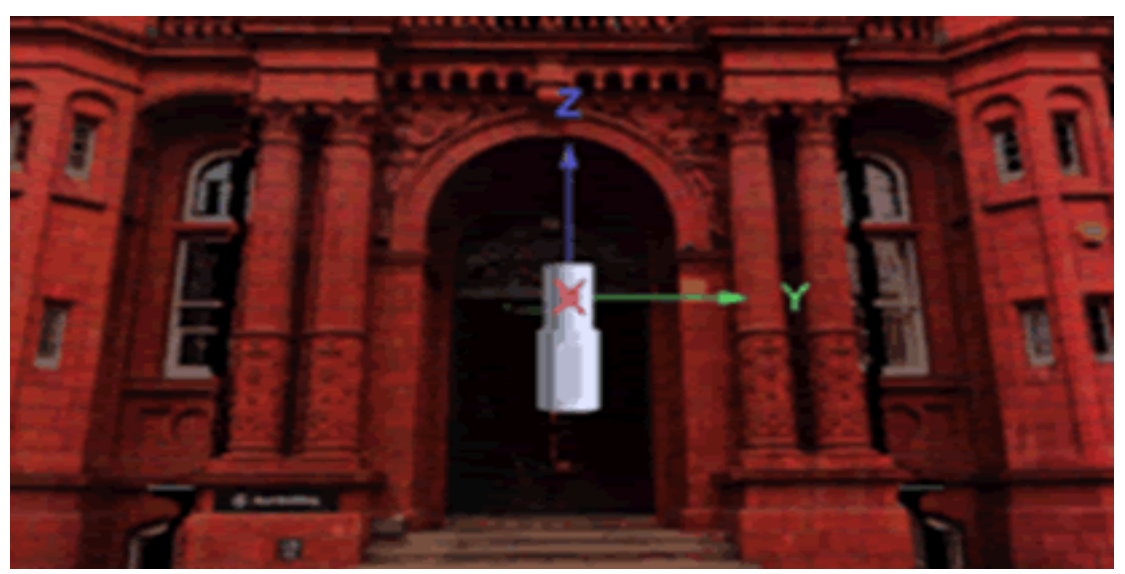

Figure 4 The Peel building front door in the campus of University of Salford

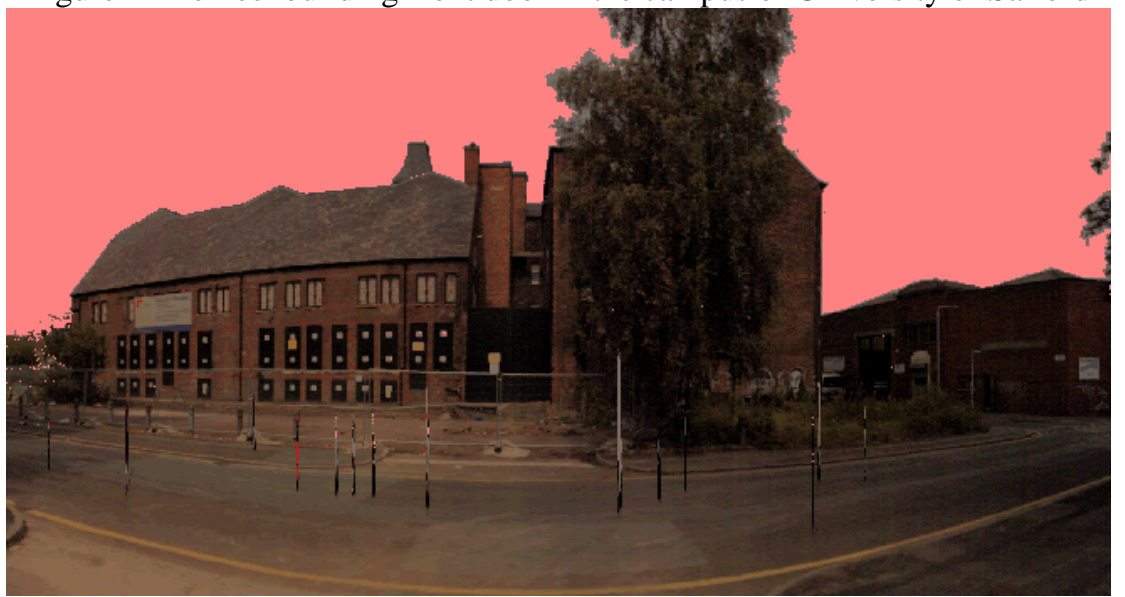

Figure 5 The back side of the Jactin House building in Manchester
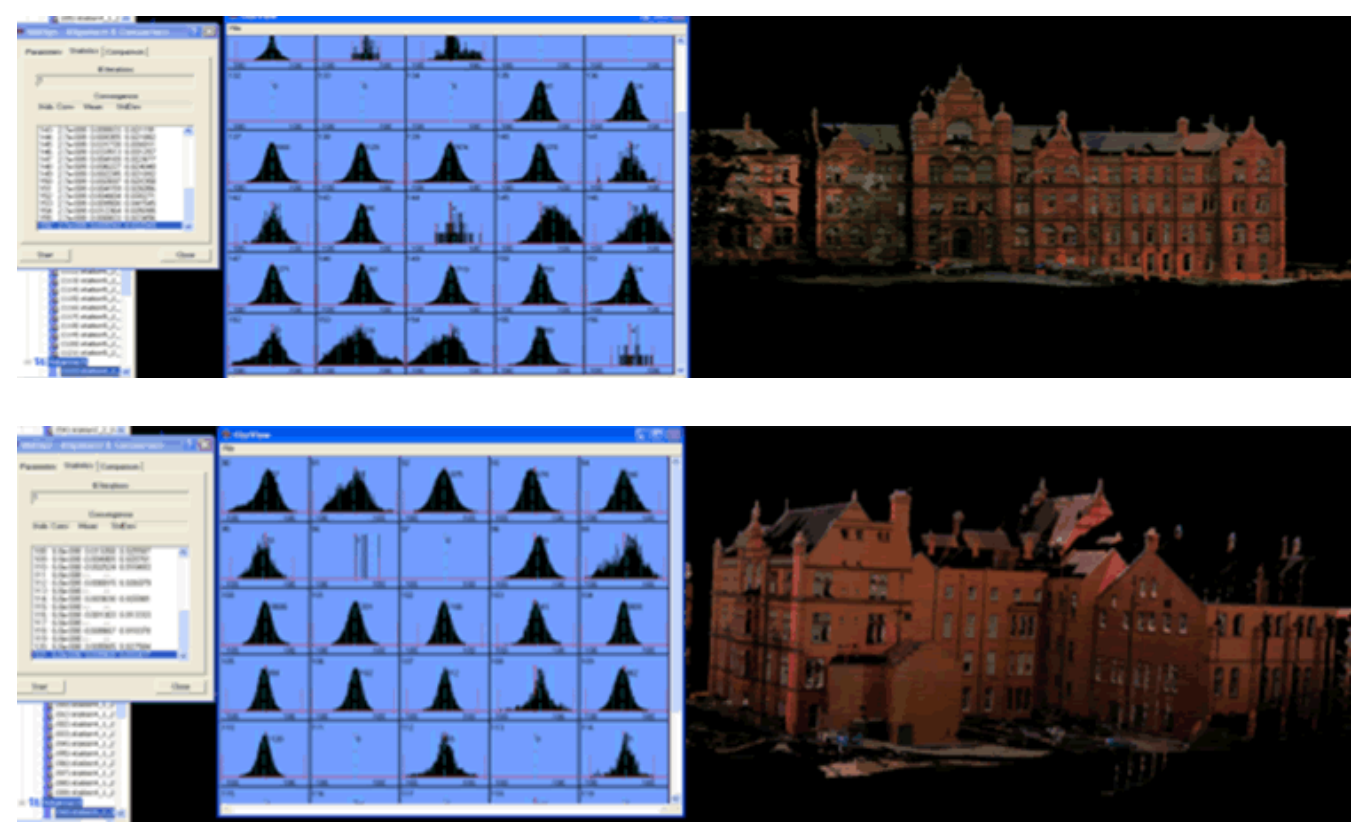

Figure 6 The Peel building scan alignment, adjustment 


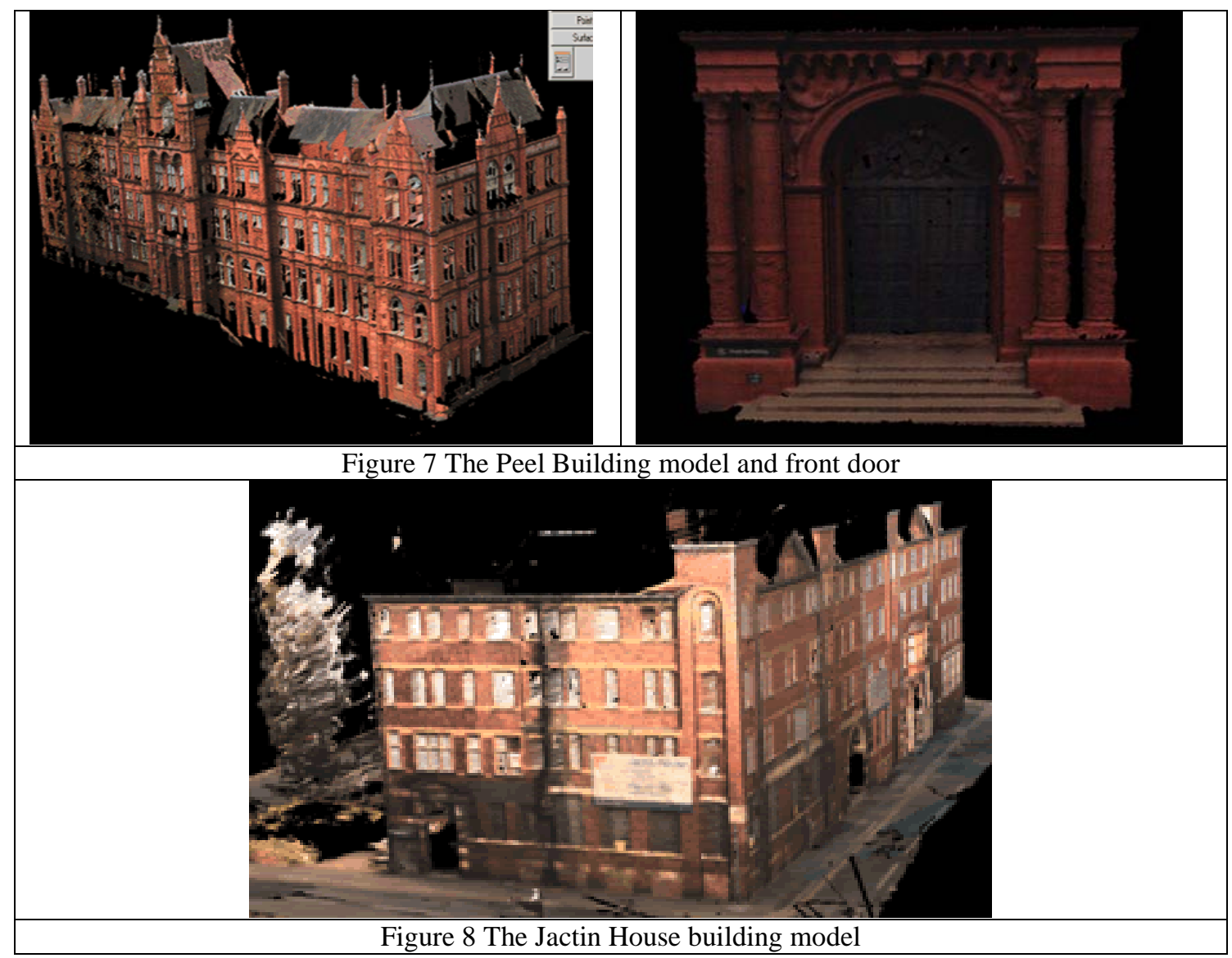

\subsubsection{Integration of the Jactin House Mesh Model with and Airborne LIDAR data and the OS data}

Integration of different spatial datasets has been an issue in the research community for the last decade. In this concept integration of airborne and ground based lidar data also has drawn some interest. Airborne lidar data and terrestrial lidar data have their own advantages and disadvantages. For example, terrestrial lidar data lacks information for building roofs whereas it can provide rich information for façade of buildings. On the other hand, airborne lidar data lacks information for façade of buildings while it can cover information for building roofs. Therefore, consolidating both types of data into one model will provide rich VR environment for urban development and environmental analysis. However, in practice we should overcome the below issues for the integration of these data:

- How to compromise a common scale: There is a big difference between each dataset. That is to say; terrestrial data has a very big scale and covers only one building, airborne data is has a very small scale while covering a large amount of buildings.

- How to compromise an average accuracy and resolution: resolution is manipulated with sub sampling and interpolation steps in the Polwyork software. The figures range from $5 \mathrm{~mm}$ to $20 \mathrm{~cm}$ for ground based lidar data, these parameters were range form $5 \mathrm{~m}$ to $0.1 \mathrm{~m}$ for airborne data. 
On the other hand, each data set differs in terms of accuracy. For example, standard deviation for mesh modeling from point cloud data were normally set $10 \mathrm{~mm}$, or $15 \mathrm{~mm}$ or $25 \mathrm{~mm}$ based on the scanning accuracy for ground based dataset; this parameter is set to $2 \mathrm{~m}$ for mesh modeling. As a result, in terms of accuracy there is big difference between both datasets.

- How to define a common coordinate system for both types of lidar data: This is the most crucial aspect between both datasets. If this issue is solved, the integration of both dataset is quite likely to be achieved.

The airborne lidar data is referenced to WGS (GPS) global coordinate system whereas the ground based data is based on a local coordinate system of laser scanner. However, this local coordinate system can be transformed into global coordinate system using control points. This translation can be done in Polwyork software. When this translation is done, both data sets can be stored in the same coordinate system.

- What is the common data standard for both types datasets: The provided airborne data is in a proprietary format, which is compatible with the ArcView software as explained in the readme document of the airborne dataset provided by Environmental agency. However, this format is recognized by the Polywrok software which can import many different datasets as given below.

In this specific case point cloud data provided in ASCII text format including xyz coordinates is imported into polywork software successful. Polywork software can import ASCII text files with RGB color information. This is useful when the ground based data is converted into ASCII text files, which includes RGB colors.

- How to recognize the targeted buildings for merging: it is not simple and easy to distinguish the jactin house building amongst the buildings without using any third party tool such as map. At building level, the jactin house data provided in the airbone data set is so coarse and at an abstract level compared to the ground based data of the jactin house building.

The post-processing, which is applied for ground-based lidar data can also be applied for the airborne lidar data as applied for East Manchester airborne data. For example, using the IMMerge model of Poywork a mesh model can be created. Due to high number of point cloud in each scan, it is not easy to import the data. For example, when the number points to be imported are over 3 millions, the software cannot handle and it crashes. Therefore it is necessary, which requires sub sampling, which filters the number of points to be imported without losing any information.

Because the individual scans are already aligned to each other, re-registration from beginning is not necessary. However, point cloud adjustment and relevant postprocessing techniques can be applied. For example, "reduced overlap" function is used to reduce the overlapping point clouds between the adjacent scans. Figure 9 shows the integrated airborne and ground based data in the Polywork software visualisation environment. 

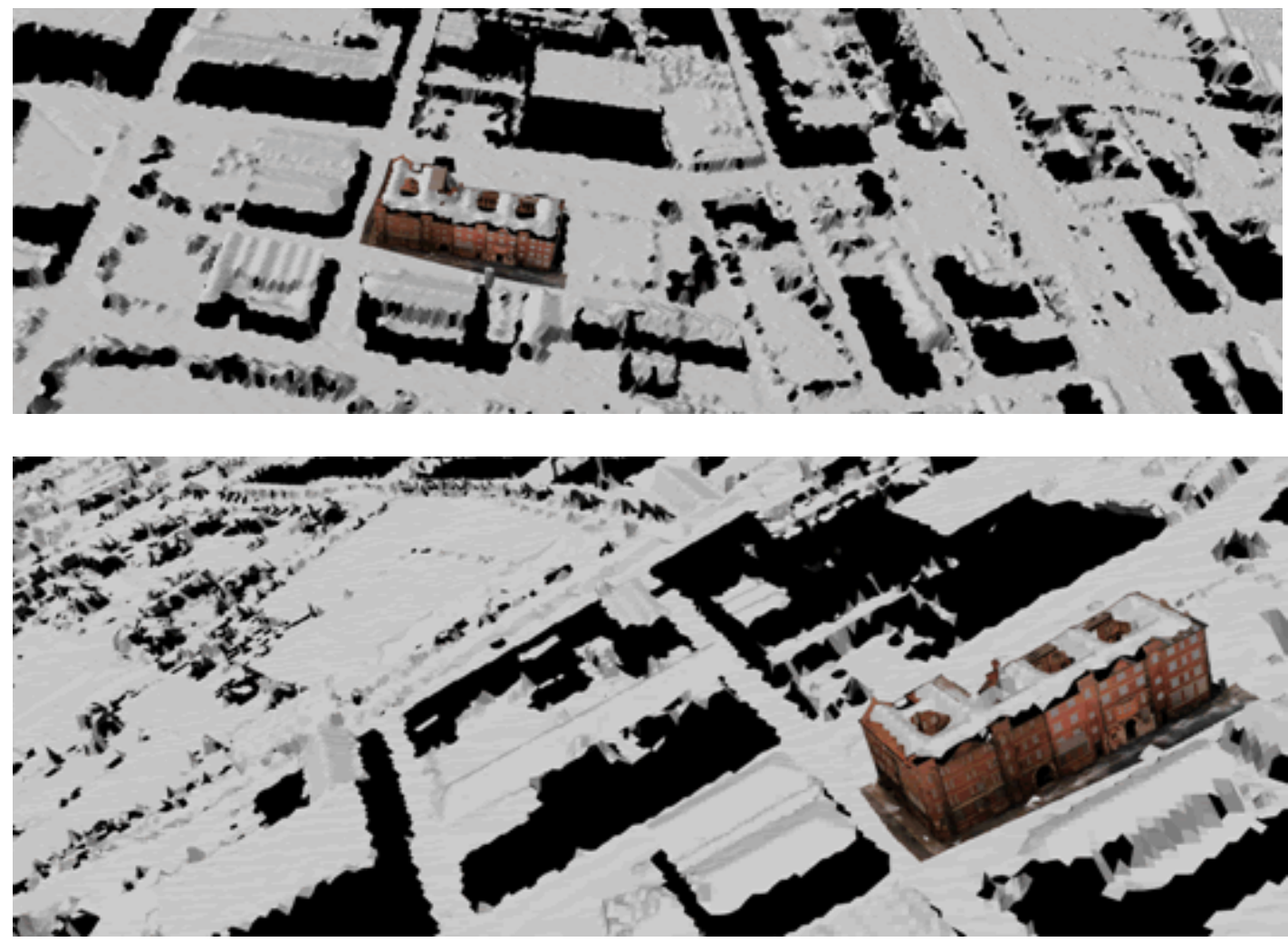

Figure 9: Integrated airborne and terrestrial datasets in the same environment

In the same process processing methodology implemented in the Polywork software, the same terrestrial data can also be integrated with OS data. However, in these circumstances the main concern is the data compatibility. The original OS data was stored in Arcview environment from where the data was exported in dxf format as polylines. However, this dxf files is not compatible with Polywork software which only accepts $\mathrm{dxf}$ files as 3D faces. Therefore, the dxf file exported from arcview was imported into Microstation environment and converted into STL files, which was imported into Polywork environment for integration. The data registration process was applied for both datasets. The integrated datasets are represented below in figure 10.

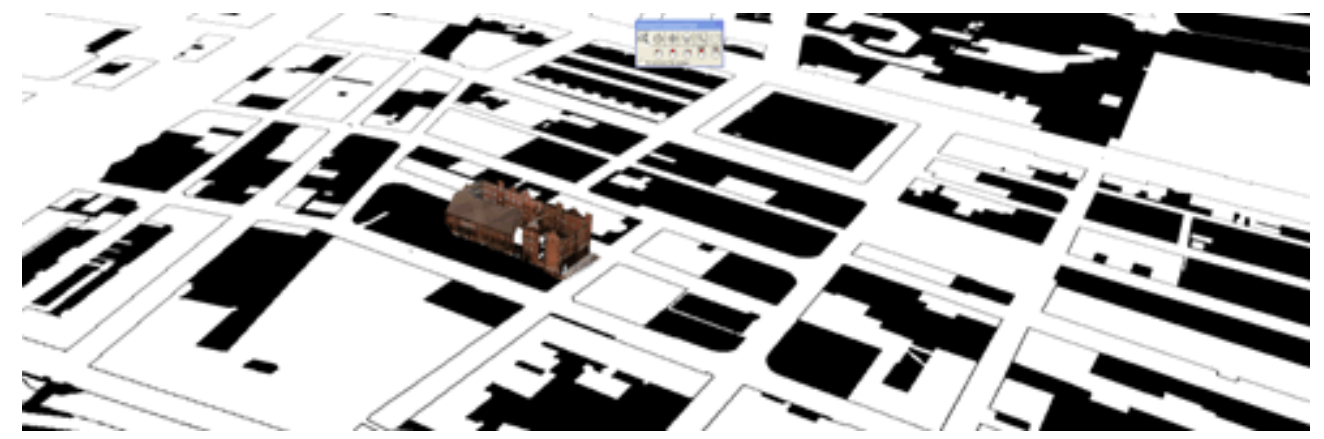




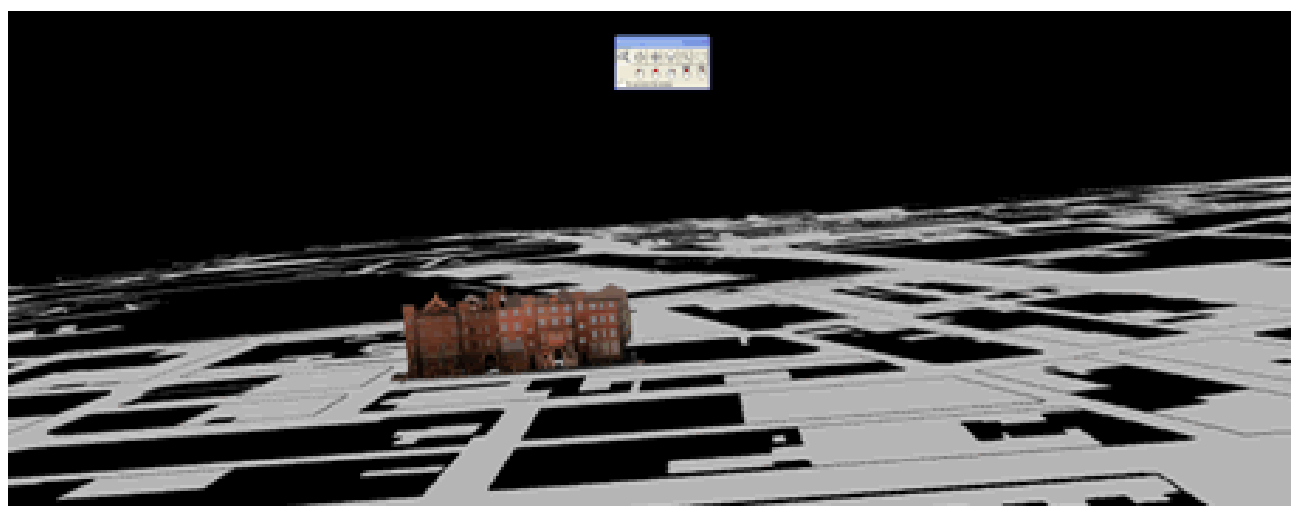

Figure 10: Integrated visualisation of the Jactin house building point cloud data with the OS data

\subsubsection{Editing the 3D Model and CAD Extraction}

The editing process starts at phase 4 . The editing process is crucial in order to produce a neat CAD model. This is done by means of the Polyworks IMEdit software module. Several steps exist in phase 4 and 5 in order to complete the editing process to a high standard:

The peel building front door image in figure 7 and Jactin House image in figure 8 also shows the models before the editing process starts for feature line extraction for CAD modelling.

Step 1_Lining up Model: The first activity in the IMEdit module of Ployworks software is to orientate the 3D Mesh model into an XYZ coordinate system. Because the model could be oblique in the space, the first step is to line up the model according to the IMEdit XYZ coordinate system. As a result, width, height and length of the model can be viewed horizontally and vertically when the model is viewed from $\mathrm{X}, \mathrm{Y}$ or $\mathrm{Z}$ perspectives of the coordinate system.

To do that, a plane object is inserted through a surface of the model by selecting 3 vertices distributed almost equally on the surface. This plane is situated through the surface. Another plane object is inserted aligned with any of XY, XZ, YZ dimensions. The second plane is situated in the space as parallel to one of the $\mathrm{XY}, \mathrm{XZ}, \mathrm{YZ}$ dimensions. Now the first plane inserted into the model surface is converted to the second plane. This also allows the model to be aligned to an intended vertical dimension such as $\mathrm{XY}, \mathrm{XZ}$, and YZ. Once this lining up process is done three times, the whole model will be converted to the XYZ coordinate system of the IMEdit module of Polyworks software.

Step 2_Plane insertion: After lining up the model to the coordinate system, it is much easier to insert planes to the model surfaces. Inserting planes coplanar with three vertices, inserting planes aligned with the coordinate system options are mostly used options because in the previous phase, the model is aligned according to the coordinate system. There are three ways of inserting planes aligned with the coordinate system of the polygonal model.

- Insert planes aligned with the X-Y Plane

- Insert planes aligned with the X-Z Plane:

- Insert planes aligned with the Y-Z Plane 
Plane insertion is important because any points diverted from the average surface can be projected using plane insertion. Without this it is not possible to produce straight lines for CAD modelling.

Step 3_Point Selection: Because vertices selection is a laborious and time intensive activity, improvement is necessary to reduce the amount of time and labour in this step. This Improvement can be made by defining a selection strategy to select all the relevant vertices on a surface in one click. For example, select a good point on the average surface and project this point on the plane inserted before. After this allow the software to select the points away from the plane at a certain distance such as $1 \mathrm{~mm}$ or $5 \mathrm{~mm}$. As a result, all the relevant points can be selected at a certain accuracy based on project requirements.

Step 4_Project Points onto Plane: After carefully selecting points in step 3, it is time to project them onto the planes inserted before. Besides projecting points onto planes, points can also be projected on the inserted surfaces when necessary. For example, when the vertices are on an arch surface area in the model, a surface which fits the surface area in the model can be inserted and the vertices can be projected on the inserted surface.

This is a straightforward process although it is necessary to pay full attention in order to avoid any clashes while making up the edges between surfaces. In case of any clash, step 3 and 4 can be repeated iteratively. If there are any arc edges on the model, curves can be used to construct sharp edges at defined deviation parameters from the curve.

Step 5_Optimize the Mesh Model: it is necessary to optimize the mesh model to make the model consistent and if necessary reduce the number of points at some regions in the model to reduce the file size and avoid point intensity and heterogenic point scatter. There are a number of parameters that need to be adjusted for mesh optimization. These are

- Sensitivity

- Minimum number of triangles per vertex

- Max number of triangles per vertex

- Min inner angle

- Max dihedral angle

The mesh optimization procedure is applied to pairs of triangles. For each processed pair of triangles, the pair's neighbourhood is checked to see if the region is concave or convex. If the neighbourhood is convex and the pair of triangles is concave, the common edge will be permuted by means of the two adjacent triangles to make the pair of triangles convex. The same operation is performed if the neighbourhood is concave and the pair of triangles is convex.

After mesh optimization, the triangulated mesh is more consistent, and the surface curvature is better described. Mesh optimization works best if the polygonal mesh is relatively smooth.

Step 6_Create Cross-sections: After completion of step 5, a regular mesh model with planes and defined edges should be in place. At step 6, cross-sections are 
created through the planes inserted into the corresponding surfaces of the model. Each cross-section will create a CAD line on the edges of the corresponding surfaces. This CAD lines describes the characteristics features of the model.

Step 7_Export Cross-section: Cross-sections can be exported in various formats such as DXF, IGES, and so on. Generally, exporting to DXF is the preferred option because it is CAD oriented format. The export of cross-sections can be done in a variety of combinations such as individually selections, all cross-sections selections or certain number of cross-section selections.

The ideal way of exporting cross sections is to export the only cross-sections that have relationships among themselves to describe a building element. With this in mind the export process should be done for each building element separately. For example, if a window in a building model were to be exported then only the cross-sections that define the edges of this window should be selected and exported. Once this has been done for each element of the model, a CAD model will result that includes all the building's elements geometry in an object-oriented manner.
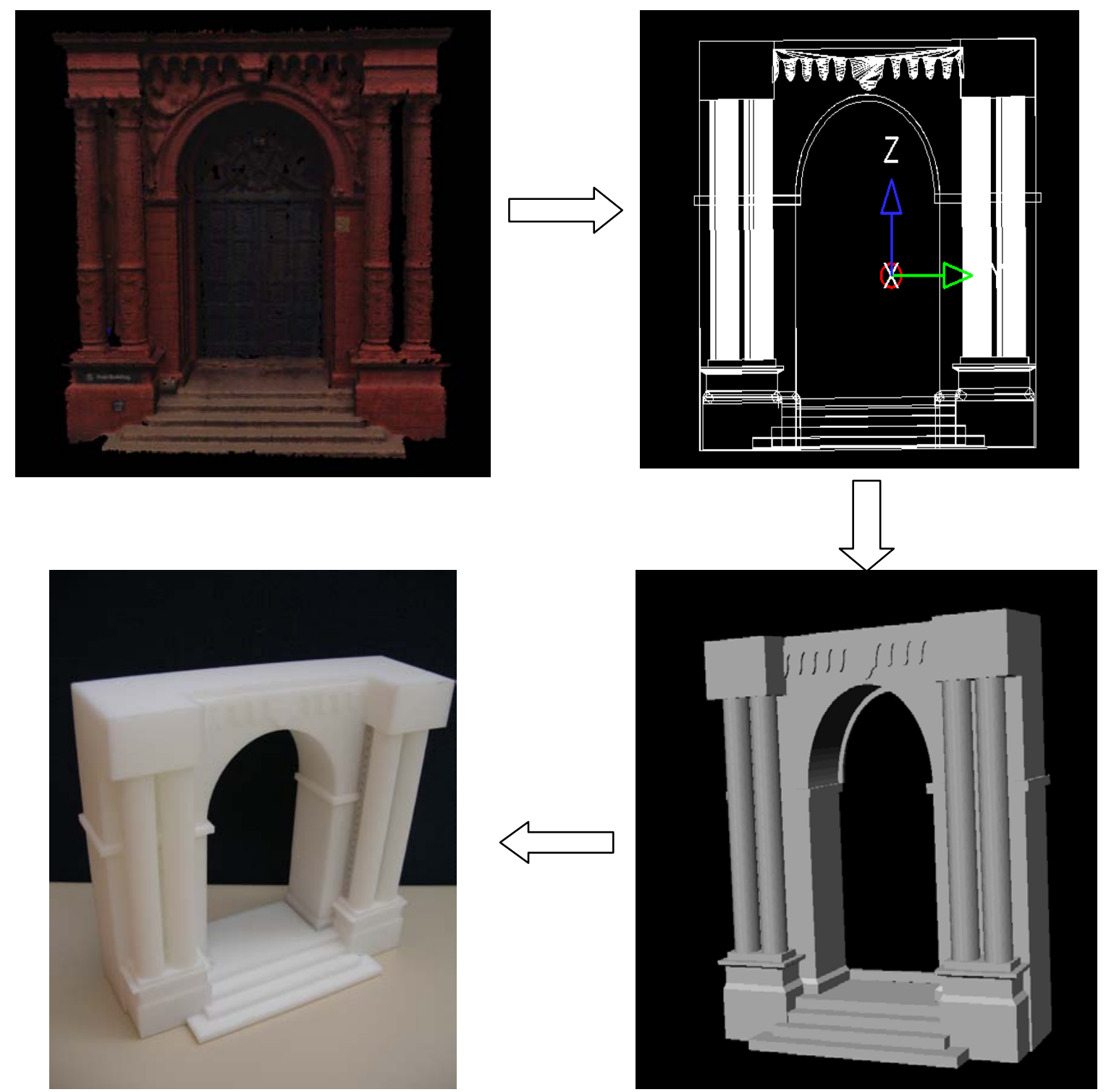

Figure 11: Peel Front door CAD extraction and plastic modelling with 3D printer 
Phase 5 is completed after completion of Step 7. The output is a 3D CAD model, which can be manipulated or edited if necessary in CAD software such as Microstation Triforma. For example, figure 11 illustrates a result of CAD extraction from the mesh model, which demonstrates the reverse prototyping for buildings using the 3D laser scanner data. This output is ready to use for building surveyors or engineers. However, to produce IFC elements, the process continues towards the stage 6 and 7. This section focuses on phase 6 and 7 in figure 2 .

\subsubsection{Object Recognition for IFC (Industry Foundation Classes)}

The object-oriented CAD modelling approach utilises the Microstation Triforma software, which employs a single building model concept. All information about a building (or at least as much as possible) is recorded in a 3 dimensional model. Traditionally a given door in a building would be drawn in at least three or four places (plan, building elevation, building section, interior elevation, etc). In the single building model, it is constructed once and these various drawings are later extracted automatically. The single building model requires building objects that are defined, edited and stored in the triforma library (See the diagram for pattern matching).

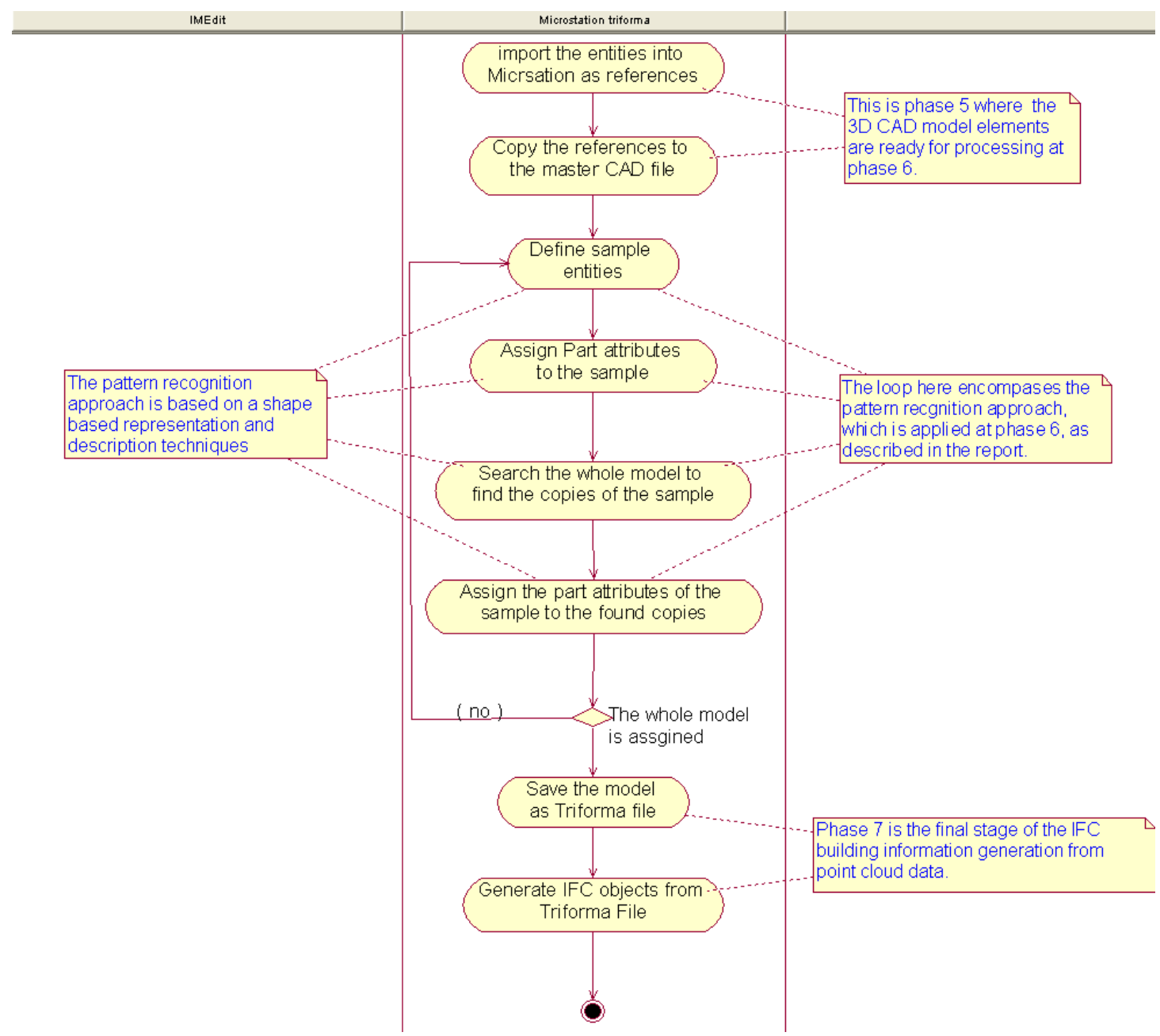

Figure 12 continues from figure 3 for object oriented CAD modelling 
There have been many researches on shape representation and retrieval at lower level, and semantic retrieval on colour image recently (Zhang and $\mathrm{Lu}, 2004$ ). To semantically annotate a shape database can be very difficult. However, if the objects are the CAD graphics as illustrated in figure 12, it is possible to annotate it automatically. There are efficient techniques available in the literature. However, a simply way is to design some templates representing each type of objects, and then mapping those new objects into templates. If there is already an annotated object database, they can be used to approximate new objects to be created.

The complexity of annotation depends on how large it is and the nature of projects. If a project is new and not large, newly created objects can be manually annotated and stored into database, so that the annotated and stored objects may be reused in the project. That is, whenever an object is necessary later in the project, it can be simply found in the database and manipulated for new situation. If a required object cannot be found in the database, it can be created and annotated before storing into the database. However, if there is a large amount of objects to be defined and annotated, which also need to be stored into the database, these objects can be defined with some object recognition techniques such as the contour based shape descriptors, like elongation, compactness, Fourier descriptors etc, normally those descriptors are size, translation and rotation invariant (Zhang and Lu, 2004).

Contour shape techniques only exploit shape boundary information. There are generally two types of very different approaches for contour shape modelling: continuous approach and discrete approach. Continuous approaches do not divide shape into subparts; usually a feature vector derived from the integral boundary is used to describe the shape. The measure of shape similarity is usually a metric distance between the acquired feature vectors. Discrete approaches break the shape boundary into segments; called primitives using a particular criterion (Zhang and Lu, 2004). Discrete approaches differ in the selection of primitives and the organisation of the primitives for shape representation. Common methods of boundary decomposition are based on polygonal approximation, curvature decomposition and curve fitting (Pavlidis, 1982). The result is encoded into a string of the general form:

$\mathrm{S}=\mathrm{s}_{1}, \mathrm{~s}_{2}, \mathrm{~s}_{3} \ldots . \mathrm{s}_{\mathrm{n}}$, where $\mathrm{s}_{\mathrm{i}}$ may be an element of a chain code, a side of a polygon, a quadratic arc, a spline, etc. $s_{i}$ may contain a number of attributes like length, average curvature, maximal curvature, bending energy, orientation, etc. The string can be used directly for description or can be used as input to a higher level syntactic analyzer (Pavlidis, 1982).

Based on the logic above, the pattern matcher in figure 12 will access the triforma library with the criteria in hand to do search and match. Two different type of matching can be done such as exact pattern matching and approximate pattern matching. Exact pattern matching consists of finding the exact pattern looked for. In the case of approximate pattern matching, it is generalisation of the pattern looked for and a determined number of differences between the pattern looked for and the objects found in the library is allowed.

As a result of various matching processes, object recognition can be worked out for the interested building frames in the 3D CAD model. Attributes of the objects matched in the library will be assigned to the building frame in the CAD model, 
which result in the building frames to be building objects defined. Subsequently, object-oriented (OO) CAD model will be obtained. This OO CAD model will be mapped into IFC schema to save and store the model in IFC data model into the $\mathrm{nD}$ modelling database. After all the entities are defined as triforma part objects, the file can be saved as a triforma file and it is now ready for IFC generation from triforma parts. The image in figure 13 shows the IFC model of the Jactin house in the Microstation triforma environment that has IFC 2X plug-in installed.

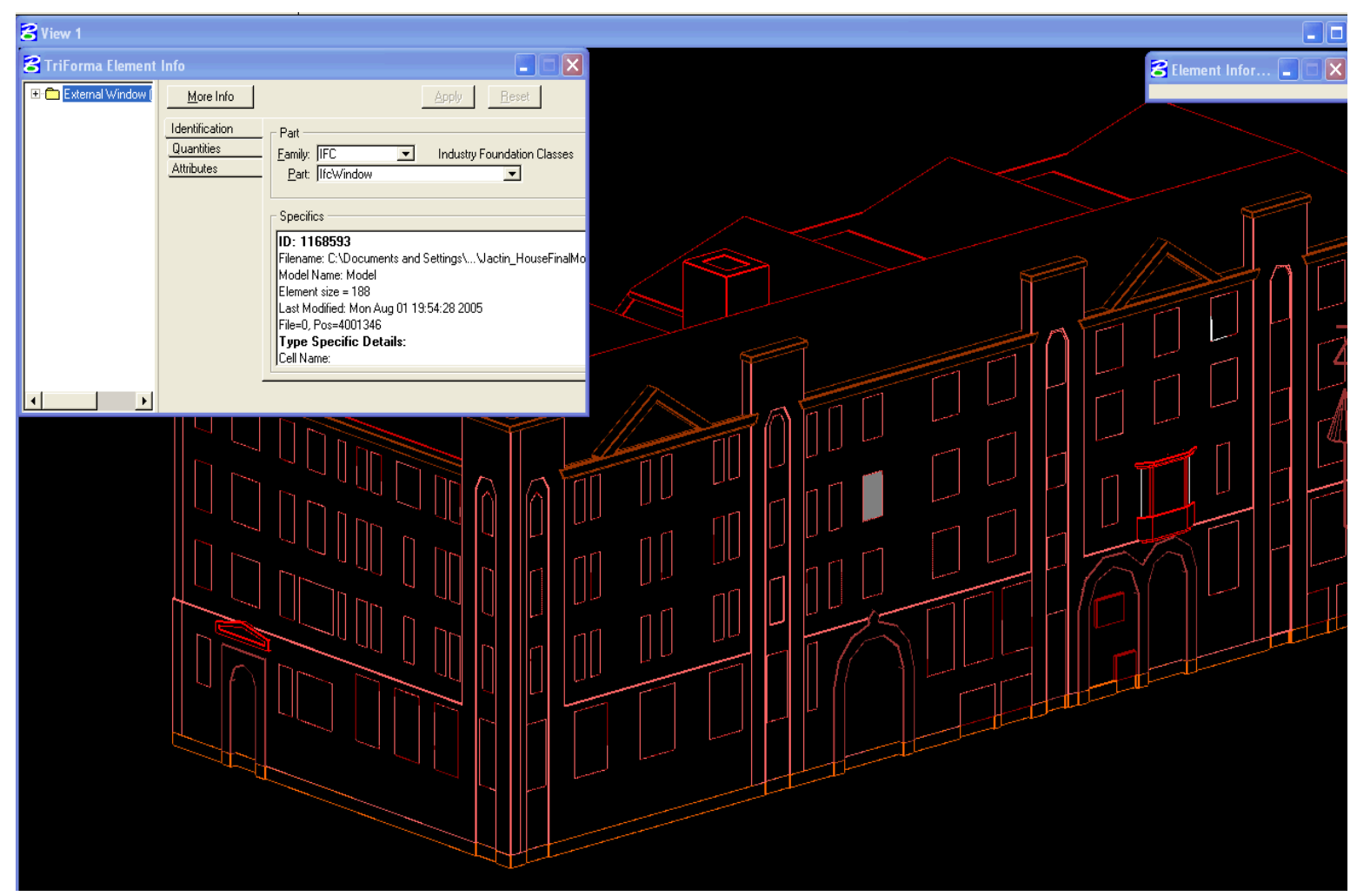

Figure 13, The Jactin House building IFC model in Microstation Triforma

\section{SUMMARY AND CONCLUSION}

In this paper, a research study regarding the processing the 3D laser scanner technology has been introduced in order to show the scope for the use of this technology in the built environment. In the paper, after literature, the intended vision is described. Following this, the point cloud data processing and modelling approach identified in the research has been introduced in the research methodology. This includes registration of point cloud data, integration with other datasets, and explanation of extraction of building primitives automatically, rapid prototyping implementation, and an approach for pattern matching for object definition. Overall, this process intends to produce CAD information and leads to pattern matching for object definition from the point cloud data.

As a result, a variety of actors can benefit from the concept explained in the paper. For instance, in regard to cultural heritage, many historical sites are slowly deteriorating due to exposure to the elements. Although remediation efforts can reduce the rate of destruction, a digital model of the site will preserve it indefinitely. Models of historical artefacts also allow scientists to study the objects in new ways. For example, archaeologists can measure artefacts in non contact fashion, which is useful for fragile objects. Also digital models allow objects to be studied remotely, 
saving time and travel expenses and enabling more archaeologists to study them. Besides, heritage manager and planning officer can utilise the system by using the building information captured by means of the laser scanner in the decision making process and for verifying the coherence between the interventions in cultural heritage and city planning because the materials, constructive pathologies and systems are often insufficient or deficient for archiving and sharing information in the documentation of historic buildings, sites and objects for refurbishment.

With regard to reverse and rapid prototyping, modelling from reality can be used to reverse engineer real objects for which a CAD model may not be available or never existed. Modelling from reality imports the real world objects into computer environment, creating a digital model that can be edited with a CAD program and then creating a physical model of the same object. This will be useful for the communication between the stakeholders in the refurbishment process, in particular client and architects, and for the publicity of the real object or building under refurbishment.

Regarding architecture and construction, architects frequently need to determine the "as built" plans of building or other structures such as industrial plants, bridges, and tunnels. A 3D model of a site can be used to verify that it was constructed according to specifications. When preparing for a renovation or a plant upgrade, the original architectural plans might be inaccurate, if they exist at all. A 3D model allows architect to plan a renovation and to test out various construction options. In regard to engineering, modelling from reality offers an efficient alternative for engineers and surveyors. For example, engineers can use the information that is converted into IFC can be used in the building lifecycle for regeneration.

\section{REFERENCES}

Allen P., Stamos, I., Gueorguiev A., Gold E., and Blaer P., “AVEBUE: Automated site modeling in urban environments", In proceeding of the international Conference on 3D Digital Imaging and Modelling (3DIM), pages 357-364, may 2001.

Andreoni D.C., Pinto L., (2004) "The Creation of the Digital Models For the Protection of Cultural Heritage: The Baptistery of Cremona”, XXth ISPRS Congress, 12-23 July 2004 Istanbul, Turkey, Commission 5, pp 489-493

Arayici Y., Hamilton A., (2005a) "Modelling 3D Scanned data to Visualise and Analyse the Built Environment", 9th International Conference of Information Visualisation, London, 6,7,8 July 2005

Arayici, Y. Hamilton A. (2005), "Built Environment Reverse and Forward Prototyping”, SCRI Symposium, University of Salford, Greater Manchester, April $12^{\text {th }} 2005$

Arayici, Y., Hamilton, A., Gamito, P., Albergaria, G., (2004) The Scope in the INTELCITIES Project for the Use of the 3D Laser Scanner, in the Proceeding of ECT2004: The Fourth International Conference on Engineering Computational Technology, 7-9 September 2004, Lisbon, Portugal. ISBN 0948749962 pp 111-112. 
Artese G., Achilli V., Boatto G., Fabris M., Salemi G., Trecroci A., "Peter Bernini in Calabria: The Sculptures of the "SS. PIETRO E PAOLO CHURCH" in Morano Calabro" in proceedings of XX Symposium of Internation Cooperation to Save the World's Cultural Heritage, Torino, italy, September 2005 pages 91-95,

Bernardini F., Rushmeier H., "Strategies for registering range images from unknown camera positions”, In proceeeddings of Three Dimensional Image capture and Applcations III, pages 200-206, January 2000

Bornaz L., Rinaudo F., 2004, Terrestrial Laser Scanning Data Processing, XXth ISPRS Congress, 12-23 July 2004 Istanbul, Turkey, Commission 5, pp514-520.

Bouroumand M., Studnicka N., (2004) "The Fusion of Laser Scanning and Close Range Photogrammetry In Bam Laser Photogrammetric Mapping of Bam Citadel (Arg-e-Bam) Iran”, XXth ISPRS Congress, 12-23 July 2004 Istanbul, Turkey, Commission 5, pp 979-983

Brasington, J., Rumsby, B.T., McVey, R.A., 2000. Monitoring and modelling morphological change in a braided gravel-bed river using high-resolution GPS-based survey. Earth Surface Processes and Landforms, 25, 973-990

Bryan P.G., Barber D.M., Mills J.P., "Towards A Standard Specification for Terrestrial Laser Scanning in Cultural Heritage: One Year on”, XXth ISPRS Congress, 12-23 July 2004 Istanbul, Turkey, Commission 5, pp-1030-1036

Campenella C., Tessoni M., Bortolotto S., Macchi A., "Methods For Dating Historical Buildings and vertically Control of the Baronale Palace at Avio's Castle”, in proceedings of XX Symposium of International Cooperation to Save the World's Cultural Heritage, Torino, italy, September 2005 pages 177-182

Capra A., Costantino D., Rossi G., Angelini M.G., Leserri M., (2005), "Survey and 3D Modelling of Castel Del Monte", in proceedings of XX Symposium of Internation Cooperation to Save the World's Cultural Heritage, Torino, italy, September 2005 pages 183-189,

Fidera A., Chapman MA., Hong J., "Terrestrial Lidar for Industrial metrology Applications: modeling, Enhancement and reconstruction”, XXth ISPRS Congress, 12-23 July 2004 Istanbul, Turkey, Commission 5, pp880-886

Fuller, I. C., Large, A. R. G., Heritage, G. L., Milan, D. J. Charlton, M. E. 2005. Derivation of reach-scale sediment transfers in the River Coquet, Northumberland, UK. In M. Blum., S. Marriott, S. Leclair, (eds) Fluvial Sedimentology VII, Special Publication, International Association of Sedimentologists, 35, 61-74.

Georgopolos A., Tsakiri M., Ionnidis C., Kakli A., "Large Scale Orthopthography Using DTM From Terrestrial Laser Scanning”, XXth ISPRS Congress, 12-23 July 2004 Istanbul, Turkey, Commission 5, pp467-473

Heritage G.L and Hetherington D, (In Press) Towards a protocol for laser scanning in fluvial, Earth Surface Processes and Landforms, Wiley, London. 
Hetherington D, Heritage G. L and Milan D.J (2005.) Daily fine sediment dynamics on an active Alpine glacier outwash plain, Proceedings of symposium S1 (sediment budgets) held during the Seventh IAHS Scientific Assembly at Foz do Iguaçu, Brazil, April 2005. IAHS Publ. 291.

Huber F.D. "Automatic Three dimensional Modelling from Reality" PhD thesis in Robotics, The Robotics Institute of Carnegie Mellon University, Pittsburgh, Pennsylvania 15213, July 2002, CMU-RI-02-35

Ikeuchi, K., Sato, Y., “Modelling from Reality” Kluwer Academic Publisher, 2001.

Levoy M., “The digital Michelangelo project”, In Second international Conference on 3D Digital Imaging and Modelling, pages 2-11, October 1099

Levoy M., Pulli K., Brian C., Szymon R., "The digital Michelangelo project: 3D scanning of large statues”, in proceedings of ACM SIG-GRAPH, pages 131-144, 2000

Li BJ., Li Q., Shi WZ, Wu FF., Feature extraction and Modelling of Urban Building from Vehicle-Borne Laser Scanning Data, XXth ISPRS Congress, 12-23 July 2004 Istanbul, Turkey, Commission 5, pp934-940

Lichti, D., 2004, “A Resolution Measure For Terrestrial Laser Scanners”, XXth ISPRS Congress, 12-23 July 2004 Istanbul, Turkey, Commission 5, pp216-222.

Miyazaki D., Ooishi T., Nishikawa T., Sagawa R., Nishino K., Tomomatsu T., Takase Y., Ikeuchi K., (2000), "The great Buddha project: Modelling cultural heritage through observation" In proceedings of the $6^{\text {th }}$ International Conference of Virtual Systems and Multimedia, pp 138-45, October 2000.

Pavlidis, T., Algorithms for Graphiques and Image Processing, Computer Science Press, Rockville, MD, 1982, p143.

Schofield, W., 2001, Engineering Surveying $5^{\text {th }}$ Edition: Theory and Examination Problems for Students, ISBN 0750649879

Stenberg H., Kersten Th, Jahn I, kinzel R., “Terrestria 3D laser scanning -Data Acquisition and Object Modelling for Industrial As-built Documentation and Architectural Applications”, XXth ISPRS Congress, 12-23 July 2004 Istanbul, Turkey, Commission 5, pp102-1017

www.riegl.com, visited in February 2007

Yamada O., Takase Y., "A Case Study for the Practical use of 3D Digital Archive of Cultural properties”, XXth ISPRS Congress, 12-23 July 2004 Istanbul, Turkey, Commission 5, pp-344-350.

Zhang, D., Lu G., "Review of shape representation and description techniques", Pattern Recognition Journal 37 (2004) 1-19. 